PAPERS IN PHYSICAL OCEANOGRAPHY AND METEOROLOGY

Published by

MASSACHUSETTS INSTITUTE OF TECHNOLOGY

AND

WOODS HOLE OCEANOGRAPHIC INSTITUTION

VOL. VIII, NO. 2

OBSERVATIONS OF ATMOSPHERIC RADIATION

BY

F. A. BROOKS

CAMBRIDGE AND WOODS HOLE, MASSACHUSETTS

October, I94I 


\section{CONTENTS}

INTRODUCTION . . . . . . . . . . . . . . . . . . . . . . . 5

Instrumentation for Laboratory Measurements of Atmospheric Emissivity and Absorptivity

Determination of Emissivities and Absorptivities of Laboratory Air a $\quad 9$

Relation Between Laboratory and Sky Measurements of Atmospheric Radiation . . . . . . . . . . . . . . . . . . . . I2

Measurements of Nocturnal Atmospheric Radiation Made Concurrently with Radiosonde Observations . . . . . . . . . . . . . . . . . . 13

Conclusions. . . . . . . . . . . . . . . . . . . . . . . . . . . .

Appendix . . . . . . . . . . . . . . . . . . . . . 18

References . . . . . . . . . . . . . . . . . . . . 22 


\title{
OBSERVATIONS OF ATMOSPHERIC RADIATION
}

\author{
F. A. BROOKS*
}

\section{INTRODUCTION}

Atmospheric radiation is the primary variable in nocturnal cooling, although wind has greater influence on the temperature of surface air. Since temperature inversions near the ground cannot be formed unless surfaces are cooled by radiation loss to the sky, a knowledge of atmospheric radiation is essential to the proper understanding of radiation frosts. The frost hazard is so serious to the citrus industry that orchard heating is practiced extensively $y^{1,2,3}$ at an average cost of more than $\$ 1,000,000$ per year.

In the special project on orchard heating carried on during the last four winters by members of the Agricultural Engineering Division of the University of California, several measurements of nocturnal radiation were made at Riverside, California in $1938-39 .{ }^{4}$ These reveal a significant relation in the change of intensity with angle of sight from the zenith to near the horizon, which is not revealed in Elsasser's ${ }^{5}$ radiation chart. It was also noticed that the Hottel \& Mangelsdorf ${ }^{6}$ measurement of water-vapor radiation over short paths indicated a rate of change with path length much greater than that derived from Elsasser's chart. These differences between observation and deduction invited further observational study, with a parallel-beam radiometer, of atmospheric radiation from short paths and from the sky, which are here reported.

The laboratory measurements (for path lengths up to 6 meters) were carried out with Professor H. C. Hottel in the Chemical Engineering Laboratory of the Massachusetts Institute of Technology. The nocturnal sky observations were made at the Harvard Blue Hill Observatory simultaneously with special radiosonde flights conducted by Dr. K. O. Lange. The same radiometer was used for both the laboratory and the sky observations.

\section{Instrumentation for Laboratory Measurements of Atmospheric Emissivity and Absorptivity}

In the present tests, the experimental apparatus consisted of three interchangeable hohlraum backgrounds (kept at about $70^{\circ} \mathrm{C}$, at room temperature, and at $-195^{\circ} \mathrm{C}$ respectively), and a shuttered thermopile radiometer that was kept free of radiating gases by flushing with dried and $\mathrm{CO}_{2}$-free air. The sensitive element was a 6 -junction symmetrical thermopile, built by Mangelsdorf (seeFig. I), which was mounted in a wooden box as shown in Fig. 2. Whenever the aperture shutter was open, external radiation reached the thermopile receiver by way of a gold-surfaced spherical mirror. Figs. I and 2 show how the small thermopile housing was diaphragmed so that the receiver coula "see" only the spherical mirror. Consequently, only a narrow beam from the outside background chamber passed through the laboratory air and impinged on the thermoelectric-junction receiver. The blackened receiver was uncovered and nonselective to wave length and was in thermal contact with the exposed junctions of the thermopile. The alignment of the

* Agricultural Engineer, California Agricultural Experiment Station, Davis, California, on sabbatical leave at Harvard and the Massachusetts Institute of Technology r 939. 
background chambers was checked optically by a light behind the receiver. The image of the receiver was about one-half the diameter of the chamber mouth.

Radiometer Response to Net Exchange of Radiation. The effective use of the experimental apparatus is based on the nearly constant temperature of the thermo-junction housing, which completely encloses the thermopile except for the small solid angle of view for the receiver via the mirror through the shutter aperture when open. When the shutter remains closed for some time and there are no strong localized heat sources in the near environment, any temperature differences in housing walls, shutter, and diaphragms disappear; the temperature of the thermopile receiver junctions become steady and the same as that of the shielded junctions. This is the condition of balance, and the galvanom-

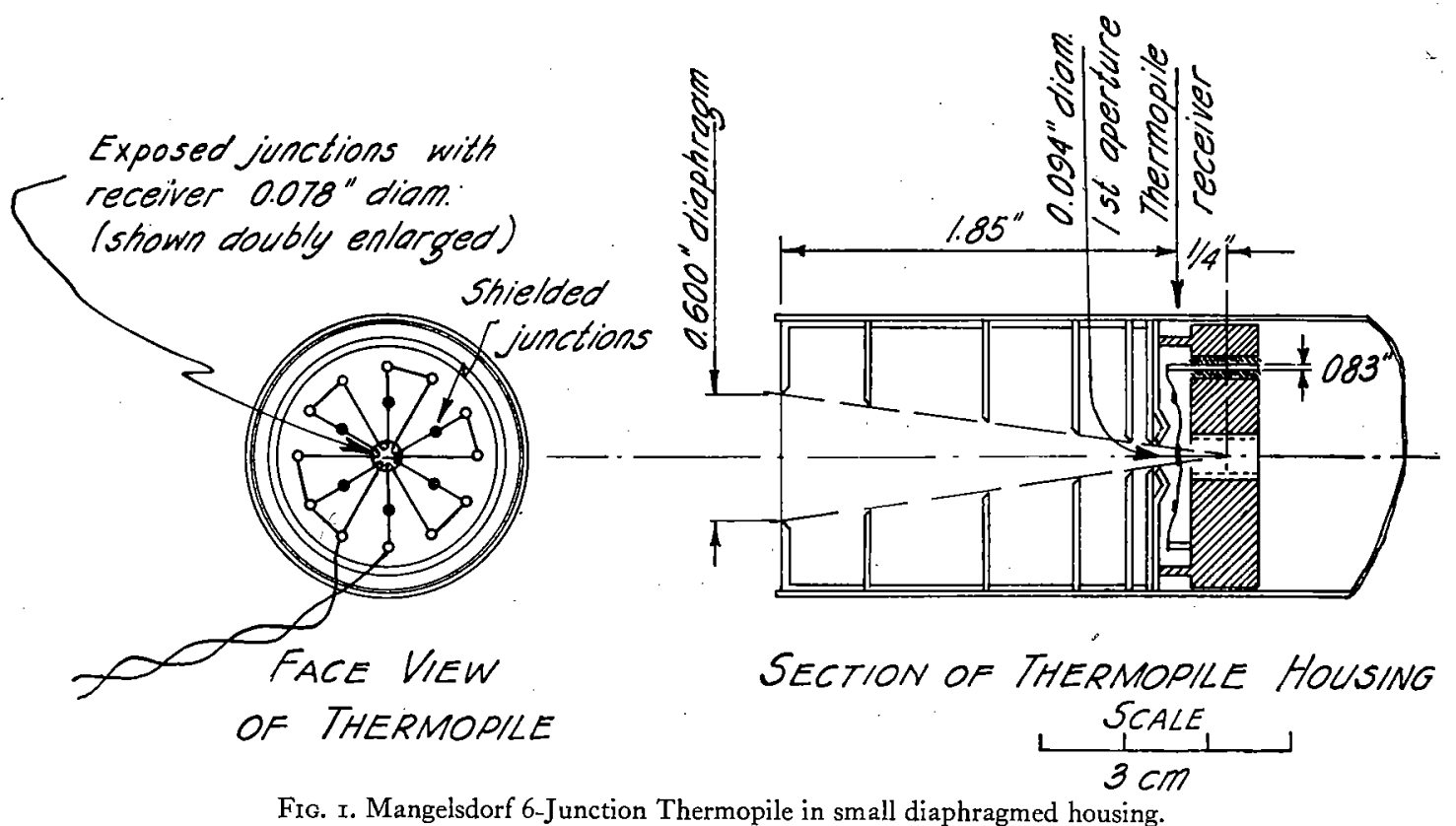

eter reading indicates a true null point. Then when the shutter is opened, the inequality between the radiant energy impinging on the receiver and that emitted by the receiver through the aperture warms or cools the receiver. The temperature gradient so established between the receiver and its close environment is just sufficient to dissipate or acquire heat to or from its small housing at the rate required by the radiant energy exchange through the aperture. The rate of flow of heat between thermopile receiver and housing is directly proportional to the temperature difference between that of the receiver junctions and that of the junctions shielded by the small housing. Hence, the thermo-electric e.m.f. generated by the thermopile is a measure of the net radiation demand on the receiver.

Use of Transient Temperatures in the Radiometer by Periodic Reading. It is to be noted that energy unbalance through the open aperture does not set up new steady temperatures in the radiometer, but establishes small transient temperature gradients. If opening the shutter allows the thermopile receiver to see a hotter surface, the temperature of the receiver will be first to rise, because of its small thermal capacity. Simultaneously the edges of the collimating diaphragms (see Fig. I), which can see some of the external hotter sur- 


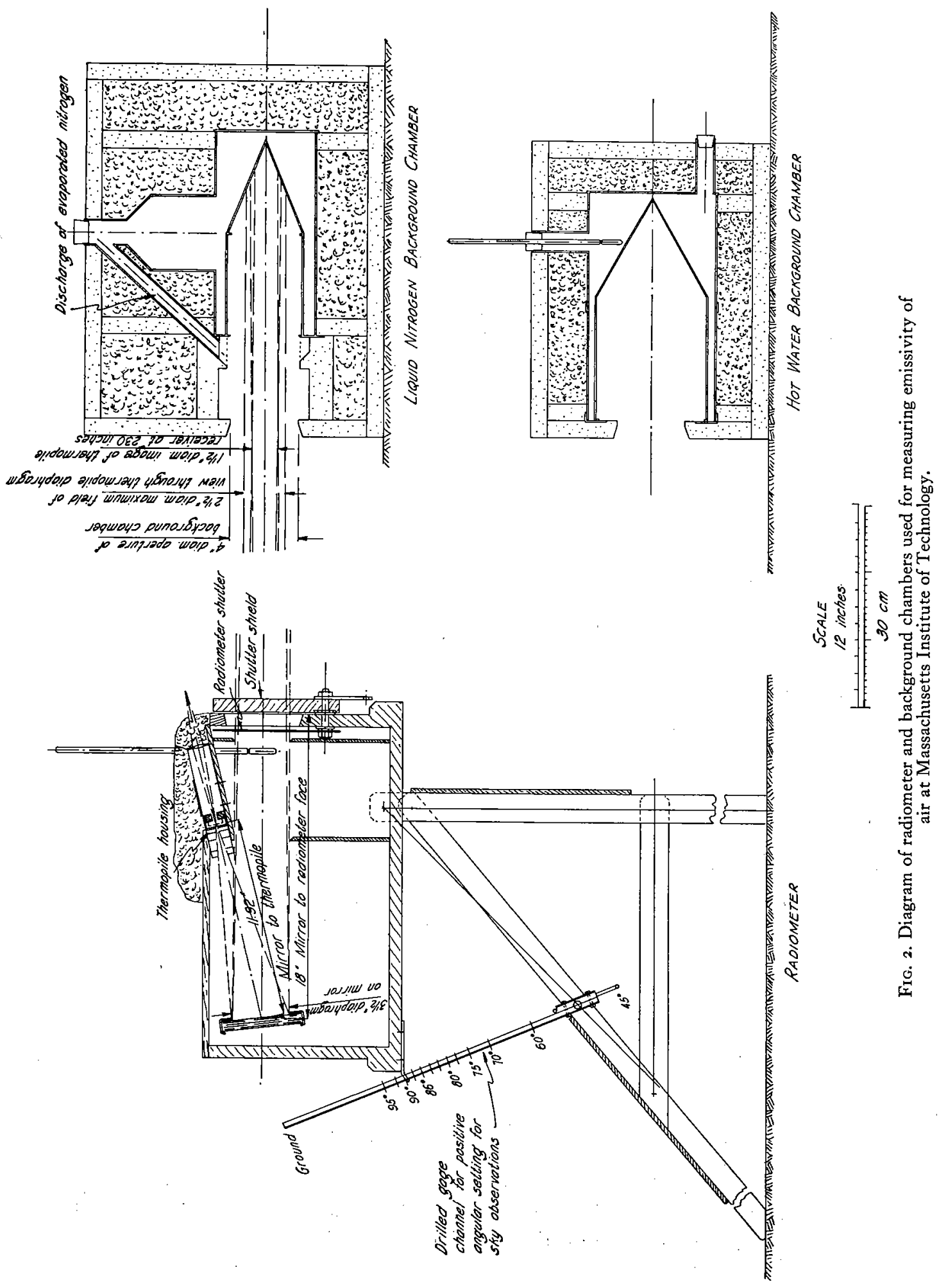


face, will be warmed independently of the receiver and at a different rate. Hence the gradients between the receiver and different parts of its immediate environment follow a complicated pattern with time. These open-shutter transient temperatures are best managed by converting them into periodic relations by reading galvanometer deflections after uniform time intervals of closed and of open shutter. Although successive deflections may not be exactly alike, due to progressive change of shutter or thermopile-housing temperatures, one can obtain reliable results by following the same procedure in calibration as in use.

Calibration. Without a large supply of nonradiating air (dried and $\mathrm{CO}_{2}$-free) a direct absolute calibration of the radiometer was impossible. There had to be a small air space between radiometer face and background face to prevent the convection currents from the hot or cold background from entering the radiometer when the shutter was open. This minimum air path is small, however, in comparison with the 6-meter observations, and for the purpose of this project might have been neglected.

TABLE I

First Trial Calibrations

(Face-to-face distance $=6$ inches)

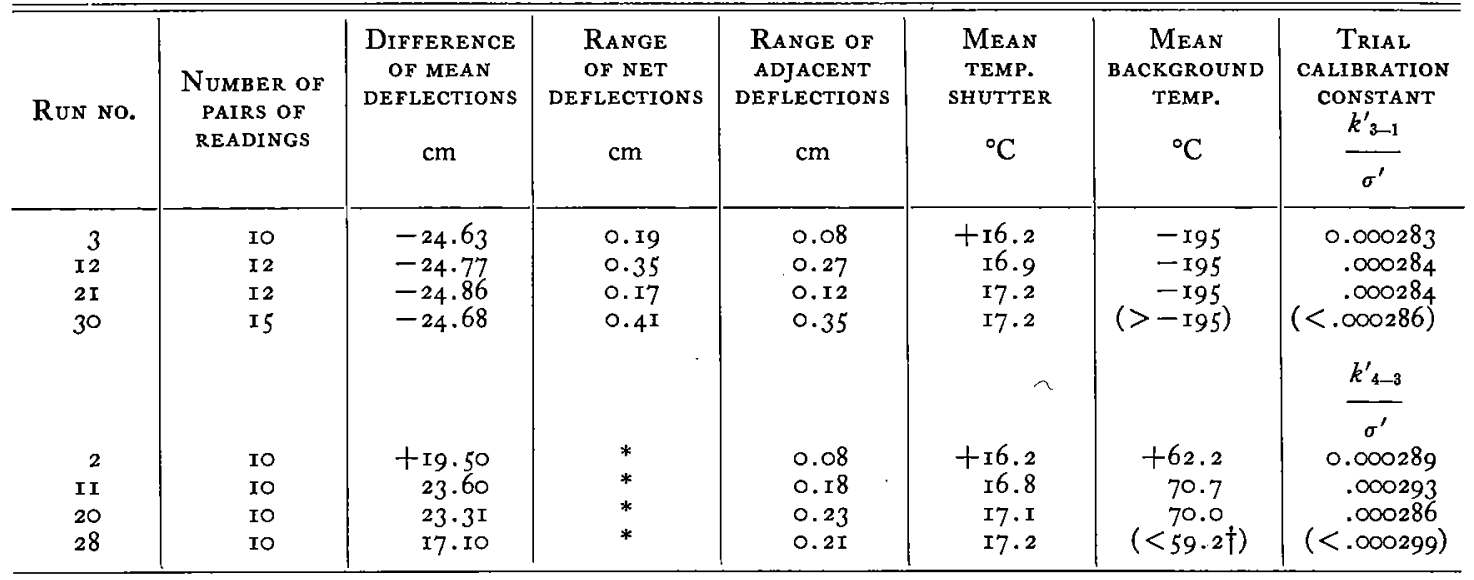

* Range for hot calibrations is meaningless because of progressive decrease in net response due to cooling of hot background.

† Thermometer raised $2 \mathrm{~cm}$ to permit reading mercury below cork top.

Table I gives the several calibration readings interspersed throughout the thirty settings made on the last day of observations (Nov. 22, I939). The readings for cold calibration were made when sighting into a hollow chamber shown aligned in Fig. 2. The blackened interior metal surfaces were kept very cold by a liquid nitrogen jacket (boiling at $-195^{\circ} \mathrm{C}$ ). The cold background chamber was refilled before runs $\mathrm{I} 2$ and $2 \mathrm{I}$, but not before run 30 . After completing run 30 the upper level of the liquid nitrogen was just above the cone centerline. The readings for hot calibration were made when sighting into a hollow chamber whose blackened interior metal surfaces were kept warm by a hotwater jacket (usually about $70^{\circ} \mathrm{C}$ ). This hot background is shown in Fig. 2 below the liquid nitrogen chamber with which it is interchanged. One sees that the cold calibrations are very consistent, the hot calibrations reasonably so. No correction is needed for first trial calculation of emissivity and absorptivity. 


\section{Determination of Emissivities and Absorptivities of Laboratory Air}

Reconsidering the previous discussion of radiant energy exchange of the apparatus, this time with special attention to the radiation effects of the air, one notes that measurements of emissivity of the air are inherently complicated by the absorption of the background radiation. And conversely, measurements of absorptivity of the air for background radiation involve the masking effect of emission by the air. Hence, one can make determinations only when the air and the background are at significantly different temperatures. As a very cold background will almost eliminate absorption effects, the emissivity determinations are practically specific when made with liquid-nitrogen backgrounds by comparing observations at a distance with the zero-path (calibration) readings. A hot background emphasizes the absorption relative to the emission effects; hence the hot-water runs are used for absorptivity determinations, observations at a distance being again compared with the zero-path (calibration) readings.

The general expression for radiant energy exchange in the test apparatus is:

or

$$
k^{\prime} D=\epsilon_{A} \sigma^{\prime} T_{A}^{4}+\left(\mathrm{I} .00-a_{A B}\right) \sigma^{\prime} T_{B}^{4}-\sigma^{\prime} T^{4}{ }_{S}
$$

$$
\frac{k^{\prime}}{\sigma^{\prime}} D=\epsilon_{A} T_{A}^{4}+\left(\mathrm{I} .00-a_{A B}\right) T_{B}^{4}-T^{4}{ }_{S}
$$

where $\frac{k^{\prime}}{\sigma^{\prime}}=$ calibration constant converting $\mathrm{cm}$ deflection to $T^{4}$

$D=$ galvanometer deflection in $\mathrm{cm}$

$\boldsymbol{\epsilon}_{A}=$ parallel-beam emissivity of the air path

$a_{A B}=$ parallel-beam absorptivity of the air path to radiation from the background

$T=$ absolute temperature

subscript $A$ refers to Air

$B$ refers to Background

$S$ refers to Shutter (or thermopile receiver).

Two unknowns, emissivity and absorptivity, appear in a single equation. Rather than neglect the small absorption of low-temperature background radiation, one should make the simple, more accurate assumption that absorptivity is equal to the emissivity for first trial calculations. Then the expression for parallel-beam emissivity is

$$
\epsilon_{A}=\frac{T^{4}{ }_{S}-T^{4}{ }_{B}+\frac{k^{\prime}}{\sigma^{\prime}} D}{T_{A}^{4}-T^{4}{ }_{B}} .
$$

In words, this equation states that the emissivity is the full calibration response, $T^{4}{ }_{S}-T^{4}{ }_{B}$ less the observed response ( $D$ is negative), divided by the full response expected from a surface at the temperature of the air (with small background correction).

The radiation path length involves both distance and gas concentration. The two factors of distance and of concentration are interchangeable for the simple carbon-dioxide molecule and for the low concentrations of water vapor found in the atmosphere. ${ }^{7}$ In parallel-beam radiation, treated in this project, the essence of path length is the number of molecules in the beam between the radiometer and the background. The moisture concentration was determined by the wet-bulb depression observed with the Julien $\mathrm{P}$. 
Friez \& Sons' precision standard motor psychrometer, both thermometers being read to $0 . I^{\circ} \mathrm{F}\left(\frac{1}{2} \mathrm{div}\right.$.). These readings taken beside the path have been reduced to vapor pressure in millibars, using Professor Ferrel's empirical formula for wet-bulb depression, as cited in Marvin's Psychrometric. Tables, ${ }^{8}$ with appropriate conversion to metric units. ${ }^{*}$

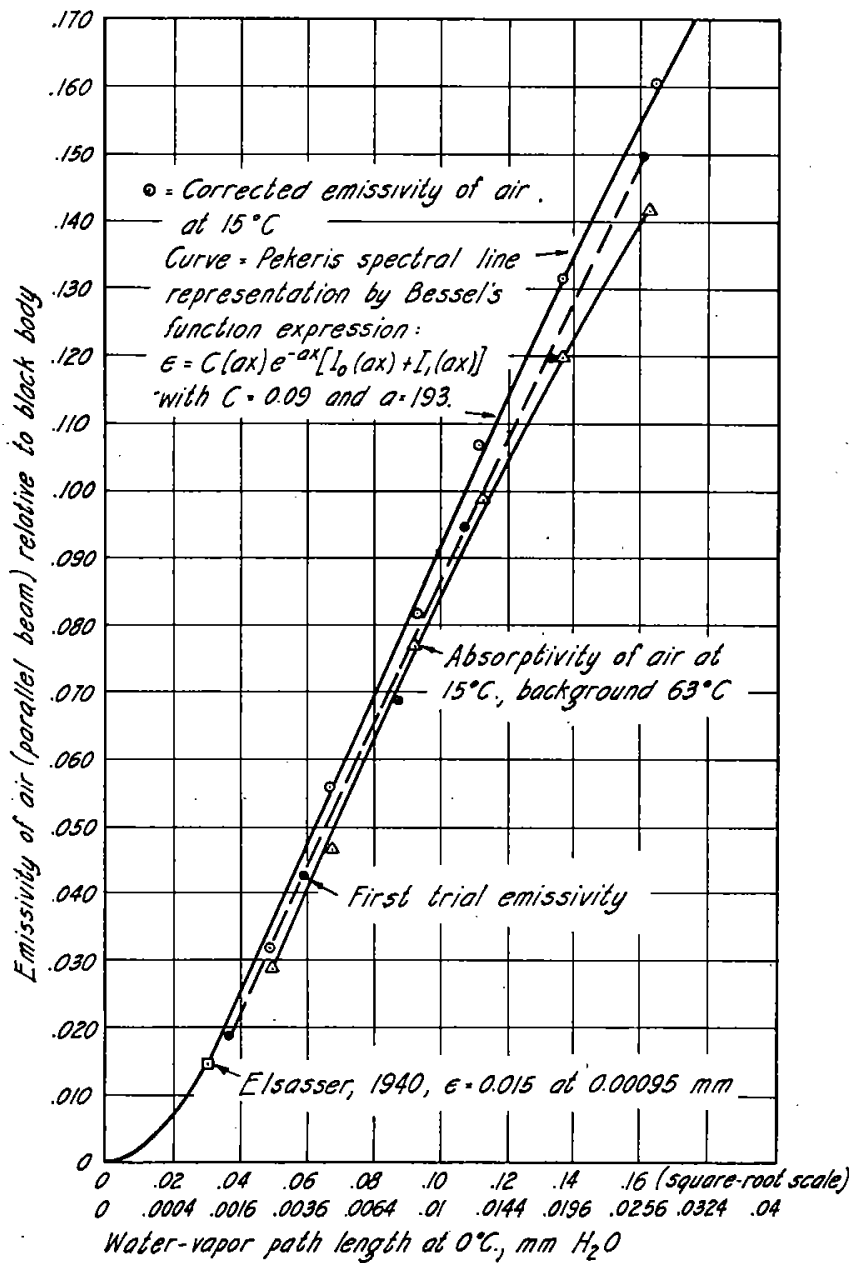

FIG. 3. Emissivity and absorptivity of air for water-vapor path lengths up to 40 meter-millibars.

Distances were measured from radiometer face to background face. The product of distance $x$ concentration (given here in metermillibars $)^{\text {) }}$ is then a measure of gaseous radiation path length. Since the laboratory temperature is higher than the average atmospheric temperature, a shrinkage correction of $273.2 / K^{\circ}{ }_{A i r}$ has been applied to all observations to reduce the path length to a standard condition of $0^{\circ} \mathrm{C}$.

Correction for Calibration Separation Distance. The minimum air path between radiometer and background exceeds somewhat the measured 6-inch face-to-face distance, because the background chambers are not perfect hohlraums. With the horizontal position used there is a convection air current inside the chamber, hence interior air radiates at temperatures intermediate between laboratory and background temperatures. In a perfect hohlraum the emission from the interior air path $(32 \mathrm{~cm}$. long) would at hohlraum temperature exactly compensate for the absorption in the same interior path. Hence, the theoretical effective plane for black-body radiation is at the opening. In the actual hot background chamber the interior air is below hohlraum temperature because the convection current of laboratory air is not instantaneously warmed to hohlraum temperature as it enters the aperture. There is therefore a deficiency of emission that leaves the interior absorption only partially compensated.

The convection current in the chamber chilled by liquid nitrogen is the reverse of that for the hot chamber. The out-flowing air, however, carries ice particles and also evapo-

* Millibars $\times 0.02953=$ inches of mercury.

$\dagger$ Meter-millibars X0.00323793= feet-atmospheres.

Meter-millibars $\times 0.0007935=\mathrm{mm}$ precipitable water. 
rated nitrogen. No correction is necessary for radiation from this outflow because the emissive power is low at these temperatures.

Revised calibration constants are recalculated from the minimum-distance runs, the first trial emissivity values being introduced for corrected minimum path lengths for both emission and absorption terms.

Corrected Emissivities and Absorptivities. With revised calibration values and corrected path distances (full setting plus small arbitrary allowances for imperfect hohlraum backgrounds), one can calculate revised emissivities and absorptivities. The results appear in Table II and Fig. 3.

If the emissivity values are plotted directly against the square-root of the path length, a straight-line relation is found, as expected by Pekeris. ${ }^{9}$ The curve fitted to the corrected

TABLE II

Corrected Beam Emissivities and Absorptivities of Air

\begin{tabular}{|c|c|c|c|c|c|c|c|c|c|c|c|c|c|c|c|}
\hline \multirow[t]{2}{*}{$\begin{array}{c}\text { Rus } \\
\text { No. }\end{array}$} & \multirow{2}{*}{$\begin{array}{c}\text { FACE- } \\
\text { TO- } \\
\text { FACE } \\
\text { DIS- } \\
\text { TANCE } \\
\\
\text { in. }\end{array}$} & \multirow{2}{*}{$\begin{array}{c}\text { COR- } \\
\text { RECTED } \\
\text { EMIS- } \\
\text { SION } \\
\text { PATH } \\
\text { DIS- } \\
\text { TANCE } \\
\text { m. }\end{array}$} & \multirow{2}{*}{$\begin{array}{c}\text { COR- } \\
\text { RECTED } \\
\text { ABSORP- } \\
\text { TION } \\
\text { PATH } \\
\text { DIS- } \\
\text { TANCE } \\
\text { m. }\end{array}$} & \multirow{2}{*}{$\begin{array}{c}\text { WATER } \\
\text { VAPOR } \\
\text { PRESS. } \\
\\
\mathrm{mb} . \\
\end{array}$} & \multirow{2}{*}{$\begin{array}{c}\text { AIR } \\
\text { TEMP. } \\
{ }^{\circ} \mathrm{C}\end{array}$} & \multicolumn{2}{|c|}{$\begin{array}{l}\text { CoRRECTED } \\
\text { EMISSION } \\
\text { PATH IENGTH } \\
\text { AI O } 0^{\circ} \mathrm{C}\end{array}$} & \multirow{2}{*}{$\begin{array}{c}\text { COR- } \\
\text { RECTED } \\
\text { ABSORP- } \\
\text { TION } \\
\text { PATH } \\
\text { LENGTH } \\
\text { AT O }{ }^{\circ} \mathrm{C} \\
\text { m-IMb }\end{array}$} & \multirow{2}{*}{$\begin{array}{l}\text { NUM- } \\
\text { BER } \\
\text { PAIRS } \\
\text { OF } \\
\text { READ- } \\
\text { INGS }\end{array}$} & \multirow{2}{*}{$\begin{array}{l}\text { DIFFER- } \\
\text { ENCE OF } \\
\text { MEEAN } \\
\text { DEFLE- } \\
\text { TION } \\
\mathrm{cm} \\
\end{array}$} & \multirow{2}{*}{$\begin{array}{c}\text { RANGE } \\
\text { OF AD- } \\
\text { JACENT } \\
\text { NET } \\
\text { DEFL. } \\
\mathrm{cm}\end{array}$} & \multirow{2}{*}{$\begin{array}{c}\text { MEAN } \\
\text { SHUT- } \\
\text { TER } \\
\text { TEMP. } \\
\\
{ }^{\circ} \mathrm{C}\end{array}$} & \multirow{2}{*}{$\begin{array}{c}\text { MEAN } \\
\text { BACK- } \\
\text { GROUND } \\
\text { TEMP. } \\
\\
{ }^{\circ} \mathrm{C} \\
\end{array}$} & \multirow{2}{*}{$\begin{array}{c}\text { EMIS- } \\
\text { SIVITY } \\
\text { PARAILEL } \\
\text { BEAM, } \\
\text { BASED ON } \\
\text { BLACK } \\
\text { BODY } \\
\epsilon_{16}\end{array}$} & \multirow{2}{*}{\begin{tabular}{|} 
ABSORP- \\
TIVITY \\
PARALLEL \\
BEAM, \\
BASED ON \\
BLACK \\
BACK- \\
GROUND \\
$a_{A_{16}} B_{63}$ \\
\end{tabular}} \\
\hline & & & & & & m. mb & $\mathrm{mm} \mathrm{H}_{2} \mathrm{O}$ & & & & & & & & \\
\hline 4 & I8 & 0.5 & 0.46 & $6 . I$ & $x_{5}$. & 3.03 & 0.0 & 2.66 & II & -24 & 0.22 & 16.3 & $-I$ & 0.032 & \\
\hline 5 & 6 & & $0.9 \mathrm{I}$ & $6 . I$ & & & & & II & & 0 & 16.3 & & & \\
\hline I3 & 7 & I. & I. 83 & $6 . I$ & I 5. & 10.99 & & I0.6I & I2 & -23 &.$T$ & 16 & & .0 & \\
\hline$I_{4}$ & Io & $2.8 \mathrm{I}$ & 2.74 & 5.9 & 55. & 15.7 & & $15.4^{\circ}$ & I2 & -22 . &.$x 7$ & 16. & -195 & .107 & \\
\hline 22 & 160 & 4. & 4.06 & 6.1 & I5. & 23.66 & & 23.30 & I3 & -2 & .27 & I 7.1 & - & .132 & \\
\hline 23 & 230 & 5.91 & 5.84 & 6.1 & I5.6 & 34.00 & .02697 & $33.6 \mathrm{I}$ & I2 & -21.24 & .20 & I7.I & -195 & .161 & \\
\hline 6 & I8 & 0 & o. & 6.2 & I5 & 2.69 & & & IO & $+I 8$ & & 16.3 & 61.8 & & 0.029 \\
\hline 7 & 36 & & I. & 6.2 & & & & & IO & & .0 & & & & .047 \\
\hline I5 & & I. 83 & $I .9 I$ & 5.9 & 15.2 & 10.28 & - & 10.74 & II & I8. & .12 & I6. & 65.0 & & .077 \\
\hline 16 & Io 8 & 2 & 2.83 & 6.0 & I5 & $15.6 \mathrm{I}$ & & 16 & IC & & & I6. 8 & & & .099 \\
\hline 24 & & & 4. I5 & 6.0 & I5 & 23. & & & I & & .1 & 17.2 & & & .120 \\
\hline 25 & 230 & 5.84 & 5.92 & 6.0 & ${ }^{5} 5.6$ & 32.96 & & 33.40 & IO & 17.28 & .21 & 17.2 & 62.8 & &.$I_{42}$ \\
\hline
\end{tabular}

emissivity values is a plot of the Ladenburg and Reiche ${ }^{10}$ Bessel's-function expression for spectral-line radiation using empirical constants as designated in the figure.

Effect of Carbon Dioxide. For the short path lengths used, the emissivities of water vapor and carbon dioxide are almost directly additive. The laboratory air was continually exhausted by a motor-driven ventilator fan, and new air drawn in through an opened window. The carbon dioxide content of this outdoor air was estimated as 0.03 per cent of the atmosphere ${ }^{11}$ (by volume). The emissivity for this concentration over the longest path length is approximately $0.018,{ }^{12}$ or about II per cent of the observed emissivity of the laboratory air.

Conclusions for Laboratory Measurements of Atmospheric Radiation. The measurements of radiation of air up to path distances of 6 meters are so well interpreted by the Bessel's-function expression for spectral-line radiation that all radiation within this path length must be of strictly spectral-line character. ${ }^{24}$ The radiative power of air with a dewpoint temperature of $0^{\circ} \mathrm{C}$ is indicated by the I 5 per cent absorption by the air of moderatetemperature black-body radiation in a distance of only 5 meters. For $10^{\circ} \mathrm{C}$ dew-point the absorption is Io per cent in $2 \frac{1}{2}$ meters. As one sees from these values of radiation from the air itself, the usual conception of radiation exchange as being confined to surfaces is inadequate if the temperature of the intervening air differs appreciably from that of the surfaces. 


\section{Relation Between Laboratory and Sky Measurements of Atmospheric Radiation}

Radiation measurements for the whole atmosphere can be made following the same fundamental principles used in the laboratory. The background of cold space beyond the atmosphere provides a parallel to the liquid nitrogen background for laboratory measurement of emissivity. The background of the moon would furnish a parallel to the hot-water laboratory background if used with such a radiometer as developed by Pettit and Nichol-

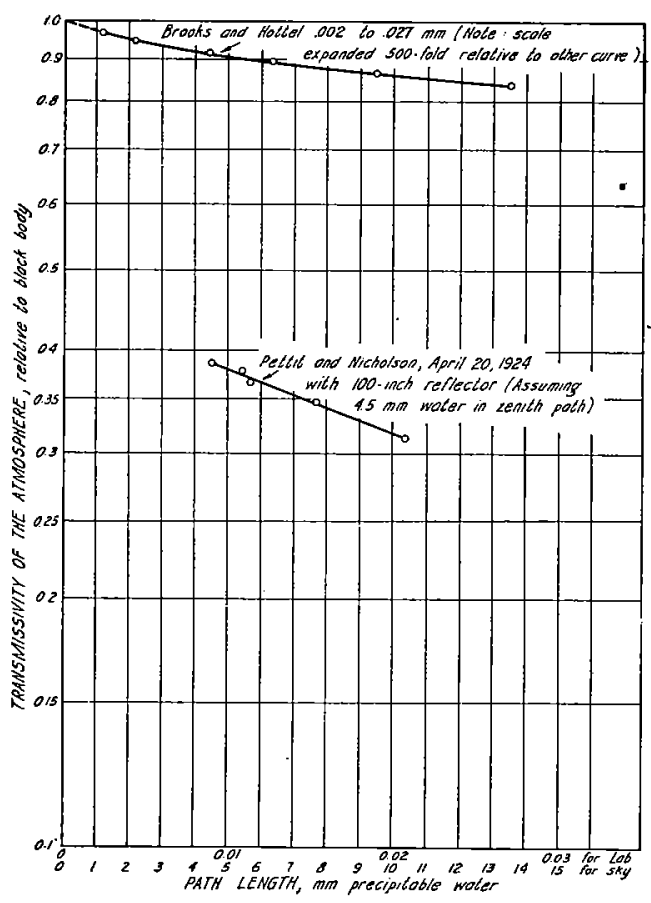

FIG. 4. Representation of atmospheric radiation in terms of transmissivity. son for the Ioo-inch reflector. ${ }^{13}$ Unfortunately Pettit and Nicholson's lunar observations ${ }^{14}$ are not directly usable for calculating atmospheric absorptivity because the image of the moon did not cover the entire area of the thermopile receiver. Observations of atmospheric emission with cold space background were made by Pettit and Nicholson ${ }^{15}$ with the Ioo-inch reflector, but for these the water-vapor path length is not known closely. These observations are of the net outgoing radiation and can readily be interpreted as atmospheric transmission as shown in Figs. 4 and 6. In Fig. 4 it is to be noted that the path-length scale of the laboratory measurements is expanded 500-fold for clear presentation.

A straight-line interpretation of the Pettit and Nicholson atmospheric observations as plotted in Fig. 4 is tantamount to adopting the analytical transmissivity expression of $A e^{-k L}$ for representing them. From the intercept at a pseudo secant of zero, $A=0.452$; and, to fit the line slope in terms of the path-length scale, the coefficient of absorption, $k=0.0352{ }^{*}$ These values for $A$ and $k$ apply only to a limited range of path length where the change in transmissivity is confined spectrally to nearly transparent regions between absorption bands. If one arbitrarily divides the spectrum into only 2 categories of short-path, absorption-band regions, and of long-path, nearly-transparent regions, then I.00- $A$, namely 0.55 , represents the short-path radiation from the water-vapor and carbon-dioxide spectral bands, and also all the ozone radiation because the latter is substantially independent of the angle of sight. $\dagger \mathrm{A}$ better understanding of this short-path radiation from $\mathrm{H}_{2} \mathrm{O}$ and $\mathrm{CO}_{2}$ can be obtained from the interpretation by Bessel's functions of absorption by spectral

* Or

$$
\log A=\frac{L_{2} \log _{10} \operatorname{transm}_{1}-L_{1} \log _{10} \text { transm }_{2}}{L_{2}-L_{1}} ; k=2.3026 \frac{\log _{10} \operatorname{transm}_{1}-\log _{10} \text { transm }_{2}}{L_{2}-L_{1}}
$$

$\dagger$ In this case of whole-spectrum radiation, it would be a mistake to take the $A$-intercept value in terms of galvanometer deflection as the zero path-length reading. The true zero-path reading eliminating short-path radiation must be the value for looking directly at absolute zero temperature, for which the galvanometer deflection can be calculated from calibration response. Clearly, therefore, the idealized single-coefficient interpretation is reasonable only over a limited range of path length. 
lines ${ }^{10}$ which includes the line wings. However, for comparison on the monochromatic basis, the single-term exponential interpretation of the short-path laboratory observations of atmospheric transmission calls for a coefficient of absorption $k \cong 80$ limited to about 17 per cent of the whole energy.

This large range of coefficient from 0.035 to 80 emphasizes the transition requirements in the intermediate path lengths. In a spectral sense the range of coefficient of absorption indicates the transition from rapid change in emissivity of spectral lines at short path lengths, to a slow change in the nearly transparent regions of the spectrum at extensive path lengths.

In the absence of radiation observations in the path-lengths intermediate between laboratory and whole atmosphere, one turns naturally to analytical deductions from molecular physics. Unfortunately, atmospheric radiation is too complicated to be treated mathematically without serious simplifying assumptions. Dr. Elsasser found it impossible to treat carbon dioxide and water vapor together. Even for water vapor alone the numerous spectral lines had to be replaced by a fairly simple curve of the mean absorption coefficient. Furthermore, an exercise of judgment was also required for the minimum value of the coefficient in the transparent region near the Io micron wave-length. These necessary assumptions in the analy tical treatment indicate the need for further direct measurements over extensive path lengths. The desired empirical curve is that of transmissivity (or emissivity) continuous from about 0.001 to $200 \mathrm{~mm}$ precipitable water.

In the absence of absolute deductions one is forced to consider an arbitrary tie bridging the gap between laboratory and sky observations. One can make this tie effectively for a limited range of conditions (nocturnal radiation frosts) if in a self-consistent system, the application of a deduced transmissivity curve to observed atmospheric conditions yields answers that match the observed radiation rates. For this purpose, radiosonde observations of moisture and temperature distributions aloft were made concurrently with measurements of nocturnal radiation intensity.

\section{Measurements of Nocturnal Atmospheric Radiation Made Concurrently with Radiosonde Observations}

Sky observations of atmospheric radiation inevitably include radiation from carbon dioxide and ozone besides radiation from water vapor. Hence, strictly, the results of this study must be considered limited to winter conditions at Boston, although any usual variations in $\mathrm{CO}_{2}$ and $\mathrm{O}_{3}$ will probably not cause much change, because of the predominance of the water-vapor radiation in the atmosphere.

A large range in moisture path lengths is possible in sky observations from a minimum of about $4 \mathrm{~mm}$ precipitable water when sighting near the zenith to practically infinite path at the horizontal sight. The moisture path length at each angle of sight is taken as the secant of the zenith distance times the zenith moisture path length. This might be known directly from spectrometer observations by Fowle's method, but is here determined from radiosonde observations. The observed vapor pressures are reduced to standard conditions by the square root of the barometric pressure ratio, ${ }^{16}$ i.e. $\sqrt{p / I_{0 I} 3.25}$.

Measurements of intensity of nocturnal sky radiation with change of angle of sight were made at the Blue Hill Meteorological Observatory of Harvard University simultaneously with radiosonde measurements of moisture and temperature distributions. The same radiometer of very small solid angle of view was used, in which the sensitive element was directly exposed without cover and responded substantially as a black body for all 


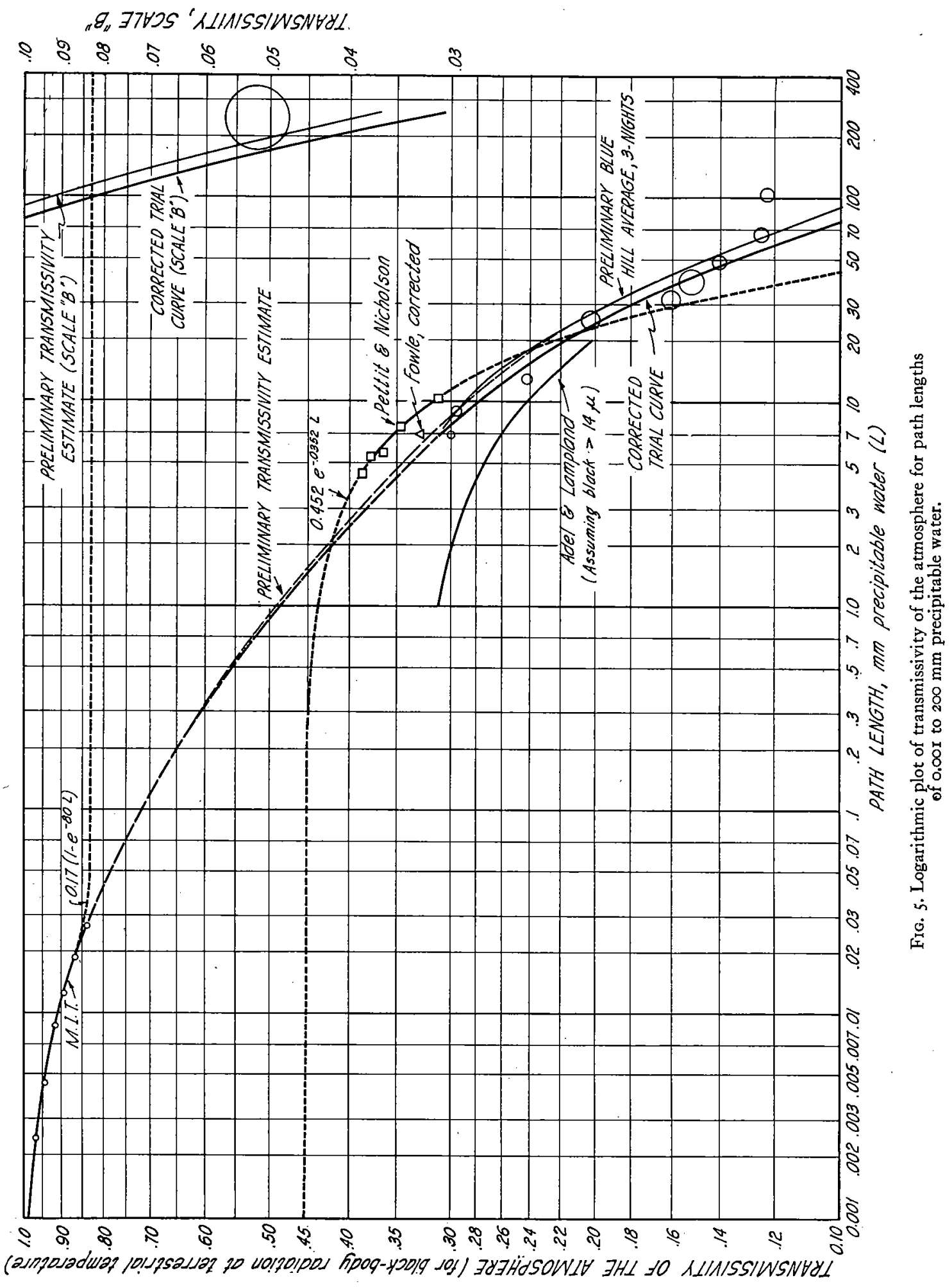


wave lengths. Twelve sighting angles were chosen with intervals varying from $20^{\circ}$ when near the zenith to $2^{\circ}$ when near the horizon.

The major part of the sky radiation comes from the air close at hand in the spectral regions of strong absorption lines and is practically independent of the angle of sight. Hence the change in radiometer response with zenith angle is due primarily to net radiation exchange in the nearly transparent region of the water-vapor spectrum (roughly 8 to $\mathrm{I} 4 \mu$ ). When, as usual, the thermopile receiver and local air are at the same temperature, the closed-shutter reading represents not only an instrumental balance point but also the level of major radiation balance. This is the null point from which deflections are measured when the shutter is open. The galvanometer deflections are then the indication of the remaining net radiation exchange that is to be evaluated relative to black-body radiation at receiver temperature. Further discussion of the measurements of nocturnal sky radiation is given in the Appendix which includes selected significant values.

Because net nocturnal sky radiation is closely represented by a true transmission, one can make a preliminary interpretation of atmospheric radiation observations at different zenith distances by the following procedure: I) Make corrections for receiver temperature so that there is zero net radiation at the horizontal sight. This would, in effect, bring receiver and local-air temperature together (where there is perfect horizontal stratification) and eliminate any unbalance due to strong short-path net radiation for receiver temperature slightly different from that of local air. 2) Base the Ioo per cent transmitted energy (by calibration) on this horizontal-base temperature. 3) Assume that the return atmospheric radiation is from an iso-thermal atmosphere at horizontal temperature so that the observed net radiation is a transmission value. 4) At first use the observed moisture in the sight paths as the moisture path lengths for the observed transmissivities. Then arbitrarily reduce moisture path length in order to compensate approximately for the deficiency of return radiation-due to the fact that overhead temperatures are below that of the horizontal. Such a correction cannot be wholly satisfactory because path length is not linearly related to emissive power. Furthermore, a correction in path length is not proper for the transmission of atmospheric radiation from beyond, because of temperature difference of intervening air. Since, however, some correction is called for, the simple ratio of black-body radiation for the two temperatures was used to establish the approximate path lengths for the preliminary atmospheric transmissivity observed for each sighting angle. These observations are plotted as circles in Fig. 5, and the solid-line curve farthest to the right is the apparent transmissivity for path lengths at various. zenith distances in the assumed isothermal atmosphere. Further discussion of the radiosonde flights including a table of averaged values is given in the Appendix.

Atmospheric Transmissivity Curve. Between the laboratory measurements and the sky observations observational data on atmospheric radiation intensity are missing between path lengths of 0.03 and $6 \mathrm{~mm}$ precipitable water. An approximately correct curve can be drawn by inspection connecting the laboratory data and preliminary sky transmissivity estimates. (See dashed line in Fig. 5.) This completes the preliminary transmissivity curve and affords an opportunity to calculate the atmospheric radiation.

Integrating under the preliminary transmissivity curve, using the moisture-temperature distributions observed by radiosonde, the calculated radiation intensity is found to be less than the measured values. This fact indicates that the preliminary curve is too low in emissivity (too high in transmissivity). By trial, a corrected curve can be found that is self-consistent. 
If in the unknown region the assumed transmissivity curve is too high, it will yield too little emissivity in those path lengths and will transmit too much from beyond. Although these errors are somewhat self-compensating, the difference in temperature distribution will reveal discrepancies. In other words, the shape of the atmospheric radiation-intensity curve from zenith to horizon ultimately defines the shape of the transmissivity curve. Of course if the radiosonde measurements of moisture, temperature, and pressure are not sufficiently accurate and if the pressure correction $\sqrt{p / p_{0}}$ is not precisely valid, the derived transmissivity curve will not be right in an absolute sense; yet it will yield consistent results for other interpretations that are made in a similar manner. Thus the observations reported herein can be useful in answering many present conjectures even though future more extensive radiation studies may yield a slightly different transmissivity curve for atmospheric radiation. The temperature distribution reported in Table IV does not yield sufficient differences to define the shape of the transmissivity curve below $6 \mathrm{~mm}$. For this purpose a larger temperature change close to the radiometer is needed.

Transmissivity of the Atmosphere to Atmospheric Radiation from Beyond. The transmissivity curve of Fig. 5 is in terms of black-body radiation intensity. That is, the ordinate values are the proportion of black-body parallel-beam radiation (at ordinary terrestrial temperatures) that passes through an air path containing the amount of water vapor indicated by the abscissa values. The shape of this black-body curve also reveals, however, the transmissivity of the air to its own highly selective radiation.

Reading the preliminary curve at path-length intervals of $0.03 \mathrm{~mm}$, one finds emissivity values (I-transmissivity) of $0.17,0.23,0.27,0.30$, and 0.32 . Evidently, although each $0.03 \mathrm{~mm}$ interval of itself has an emissivity of 0.17 , the amount of radiation it contributes to the base surface decreases very rapidly with increased intervening air path. That is, the second interval contributes but 6 per cent (i.e. .23-.I7) and the fifth interval adds only 2 per cent (black-body) to the base surface, whereas the $0.03 \mathrm{~mm}$ interval adjacent to the surface contributed $I 7$ per cent. Hence the transparency of an air path of $0 . \mathrm{I} 2 \mathrm{~mm} \mathrm{H} \mathrm{H}_{2} \mathrm{O}$ is $0.02 / 0.17=\mathrm{I} 2 \%$ for the selective radiation from an $0.03 \mathrm{~mm}$ path of the air itself. For different-sized intervals the transparencies would be different.

In using the transmissivity curve directly for determining atmospheric radiation from given moisture and temperature distributions, one need not consider the transparency of air to atmospheric radiation. The reason, as in the last example above, is that an interval contribution of 2 per cent of black-body gives the same energy as $\mathrm{r} 2$ per cent of the selective radiation, which is itself $\mathrm{I} 7$ per cent of black-body. Hence, for any given interval of path length one need only apply the emissivity indicated by the difference of black-body transmissivity values (for each end of the interval) wherever the interval may come relative to the base surface. Thus for any sighting angle the radiation intensity impinging on the base surface is then the integration, over the entire path length, of the emissive power in accordance with the temperature distribution.

Radiation charts such as those of Mügge and Möller, ${ }^{17}$ Elsasser, ${ }^{5}$ and Ashburn ${ }^{18}$ are constructed for graphical integration. On these charts, for any one temperature, the segmental areas for given intervals of water-vapor path length become rapidly smaller with distance from the base surface, in the same manner as the emissivity for given pathlength intervals along the transmissivity curve in Fig. 5. Because the contribution of a given path-length interval decreases rapidly with distance from the base surface and because there is no need of using uniform intervals of path length, it is more convenient in calculating atmospheric radiation to use uniform intervals of emissivity. For the pre- 
cision of integration needed to fit by trial the transmissivity curve to the zenith-tohorizon sky radiation observations, the arithmetic summation of the emissive powers of finite path-length intervals is much faster than graphical integration of a chart. Readings of the preliminary transmissivity curve, Fig. 5, afford values for a table of path-length vs.

TABLE III

Corrected Trial Curve of Parallel-Beam Atmospheric Emissivity with Example Calculation of Intensity of Nocturnal Incoming Radiation

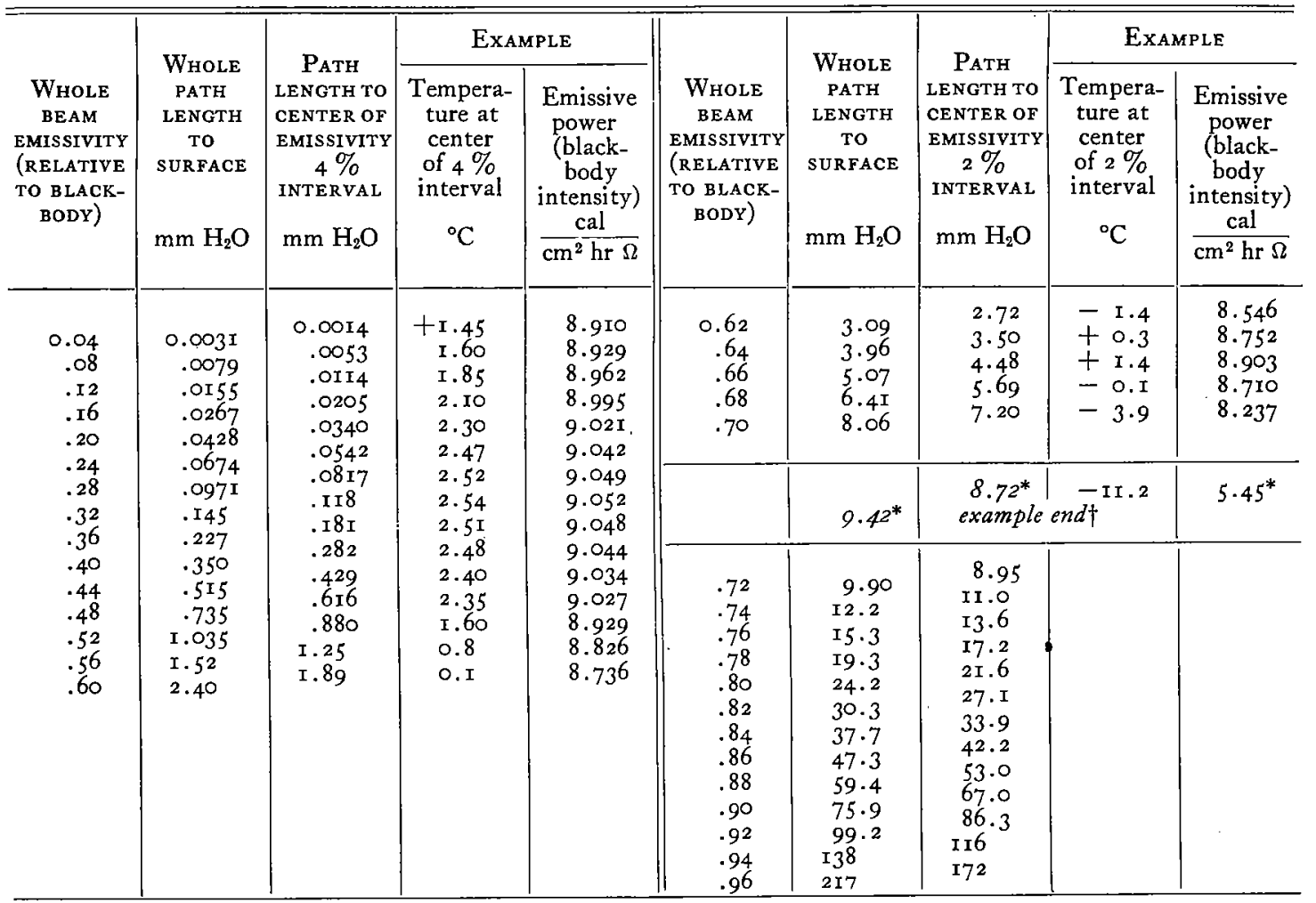

Example sum of black emissive power $=\mathrm{r} 34.604$

Example sum of black emissive power $=48.598$

$$
\begin{aligned}
& 0 \text { to } 0.60: 4 \text { per cent emissive power }=5 \cdot 3^{84} \\
& \text {. }
\end{aligned}
$$

* Total moisture in this example is $9.42 \mathrm{~mm}$, so the last interval is $\frac{3}{4}$ normal. Hence the black radiation for this interval is arbitrarily reduced to $\frac{3}{4}$. Correspondingly the mean temperature for the reduced interval is that found at $\frac{3}{4}$ of the half-interval (8.06 to 8.95 ) namely at $8.7^{2} \mathrm{~mm}$.

$\dagger$ Note: This ending neglects the remaining radiation from carbon dioxide and ozone which may be important for surfaces at high altitudes.

emissivity that can be used to calculate incoming radiation as in the example given in Table III. This was the method used to establish the corrected transmissivity curve to match the sky-radiation measurements.

The corrected trial transmissivity curve is the left-hand one shown in Fig. 5. Table III gives the corresponding emissivity values. The expected accuracy is indicated by the size of plotted circles in Fig. 5, further modified by the $\pm 2 \%$ error in the calibration and by the error in radiosonde measurements. 


\section{Conclusions}

With this curve of atmospheric parallel-beam radiation one can obtain reasonable answers to many difficult questions regarding outdoor heat transfer, such as the noctural rate of cooling of leaves on the sides of trees, if the moisture and temperature distributions in the air overhead are known.

The parallel-beam radiation values can by proper integration be converted to hemispherical radiation for a horizontal surface. Fair estimates of winter whole-sky radiation can be determined from the intensity at a sighting angle of $45^{\circ}$ by multiplying by $\mathrm{I} .02 \pi$.

More specific interpretation could be made of future measurements of atmopsheric radiation if observations are made at the edge of the Grand Canyon at a location where horizontal sights could be had simultaneously both over several miles of level ground during a strong temperature inversion, and over canyon space where the normal lapse rate would be undisturbed.

The author's thanks are extended to Professor Charles F. Brooks, Director of the Blue Hill Observatory, Harvard University, who placed the facilities of the observatory at the disposal of the author, made many of the temperature, humidity, and radiation observations, and assisted in other ways; to Dr. Karl O. Lange of the Observatory staff, for three radiosonde flights; and to Professors W. G. Whitman, S. Petterssen, and to Professor H. C. Hottel of the Massachusetts Institute of Technology, who provided for and helped in the making of the radiometer. Mr. Edward V. Ashburn of the U. S. Weather Bureau (now at Los Angeles) and Mr. J. H. Conover of the Blue Hill Observatory staff very kindly ran late galvanometer tests. Also, Mr. D. L. Arenberg of the Blue Hill staff aided in analyzing local air conditions. Recognition is gladly given Dr. W. P. Berggren and Dr. G. A. Baker of the University of California at Davis, who were of great assistance in deciding upon the analytical and statistical treatment. In fact, the work reported herein is an excellent example of willing cooperation by many others in forwarding the special interests of the author.

\section{APPENDIX}

Instrumentation and Interpretation of Sky Observations. The narrowness of the solid angle of sighting by the radiometer is indefinite because of mirror defects, but can be judged by the reversed net response during the passage of the full moon when within 5 minutes the apparent sky temperature changed from $-21.7^{\circ} \mathrm{C}$ to $+20.4^{\circ} \mathrm{C}$ and back. The radiometer was mounted inside the kite house of the Blue Hill Observatory at an elevation of 204 meters, and the opening (facing S.E.) was boarded in to the radiometer face to minimize wind disturbance.

Despite these precautions the galvanometer response was rarely steady. Hence multiple readings were made to obtain more reliable values for each angle of sight. Statistically, the average standard error based on the scatter of readings for each sighting is about 3 per cent of the net zenith radiation intensity. A total of six complete traverses were made from near zenith to ground, each traverse including fifteen sighting angles, eight near the horizon being at $2^{\circ}$ intervals. ${ }^{*}$ Three special radiosonde flights were made during the radiation measurements, one each on Nov. 23, 26, and 28, 1939, respectively.

Reduction of Galvanometer Readings. In the systematic operation of the radiometer at each angle of sight, readings were made with the shutter closed, then open, and so on for several pairs, ending with the shutter closed. Usually five or four readings were made at

\footnotetext{
* The average difference in response between the horizon and $2^{\circ}$ above is 15 per cent of the zenith net radiation.
} 
timed intervals for each shutter position, but for traverses Nos. 4 and 6 many very fast readings were made each time in order to follow the galvanometer swings closely.

The sets of multiple readings permit the use of three significantly different methods of reduction. System A, using the deflection seen $\mathrm{I} 5$ seconds after opening or closing the shutter and discarding the first closed- and open-shutter pair, follows the laboratory practice. The average standard error for this method is rather large-namely, Io per cent of the zenith net radiation. System $B$ makes use of all readings, the significant response being the difference between the arithmetric means of closed-and of open-shutter readings for each angle of sight. The great improvement in reliability in this system of interpretation is seen in the smaller standard error, averaging about 3 per cent of the net zenith radiation.* The third method of interpretation, system $\mathrm{C}$, is the use of the central median values instead of means. This method diminishes the effect of extreme galvanometer deflections that are caused by sudden air change at the thermopile. $\dagger$ In this system, again, all the readings are used, including the first pair sets. The standard error for these differences of medians would be 25 per cent ${ }^{19}$ greater than those calculated by the means, system $B$.

The useful value taken for each angle of sight is the weighted average of the values obtained in each method, the weighting being inversely as their standard errors. These weighted averages are used for plotting Fig. 5, and the corresponding weighted average standard errors are indicated by the radii of plotted circles.

Because of the strong effect of nearby moisture and temperature (about half of the total incoming atmospheric radiation arises in the first 250 meters), the radiometer will not measure atmospheric transmission to space alone unless the receiver has the same temperature as local air. The first adjustment of radiometer net readings, accordingly, is to base the net exchange on local air temperature. The algebraic addition of the outgoing black-body radiation at local air temperature and of the net sky radiation is the observed incoming atmospheric radiation intensity.

Calibration. Calibration was carried out once each night of observation, a jacketed black hollow chamber heated by hot water being held close in front of the radiometer. The equipment is described in connection with Fig. I. As there was no mechanical arrangement for supporting the hot chamber outside the kite house, some difficulty was experienced in alignment. The maximum calibration deflections yield, however, consistent results in the last two of three calibrations. The first calibration shows a low response and is assumed not to be applicable because its use would indicate much less radiation cooling on Nov. 23 than on Nov. 28, a result not to be expected from the relatively drier air of Nov. 23. This first calibration is accordingly abandoned in favor of the bettersubstantiated calibrations, from which it appears that the best value for the calibration constant $k^{\prime} / \sigma^{\prime}$ is 0.00059 with a possible range of \pm 5 per cent. This constant applies only to the net radiation, which is about $\frac{1}{3}$ of the total atmospheric radiation. The possible range in the calibration constant is comparable to an error of $\pm \mathrm{I}^{\circ} \mathrm{C}$ in the temperature of the receiver and has very little influence on the shape of the curve of net sky radiation from zenith to horizon.

Determination of Incoming Radiation Values. The moisture and temperature distributions in the atmosphere are, on clear nights, rather stable and are stratified horizontally.

* Note: The average difference of net sky response with and without the first pair of sets of readings is less than 2/IO of I per cent. Steady laboratory observations showed a $x$ per cent overresponse in the first pair.

$\dagger$ Note: A temperature change of only $0.0 I^{\circ} \mathrm{C}$ of the exposed junctions would produce a greater deflection than the largest departure observed. 
Hence the change in radiation from one sighting angle to the next should be gradual, and primarily in accordance with the change of moisture path length (indicated by the change in the secant of the zenith angle). Comparison of radiation values for successive angles of sight, however, reveals some inconsistencies. For instance, the $78 \frac{1}{2}^{\circ}$ value for traverse No.

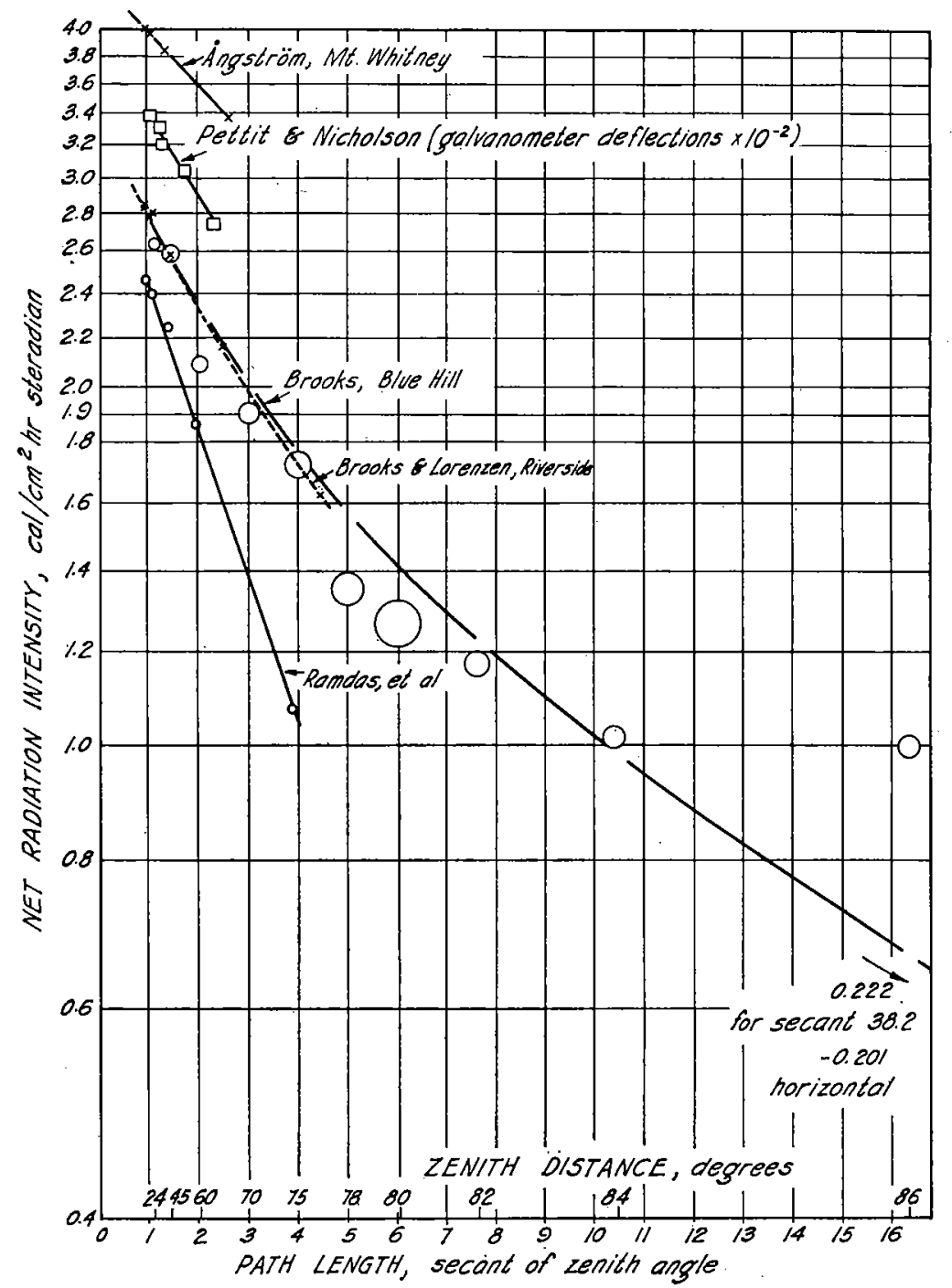

Fic. 6. Semi-log plot of the 3-night average of observed net radiation intensity and of traverses by Ångström, Pettit, and Ramdas.

I is obviously out of line. A similar departure at $84^{\frac{1}{2}}{ }^{\circ}$ in traverse No. 3 is explained by the note "cloud edge" on the original data sheet. The sky during the three night runs was never entirely clear, and the angles to cloud boundaries were judged by eye. Since clouds have high emissivity and in these cases were at temperatures much higher than the air beyond, the radiation from clouds would be much greater than from clear sky. As radiation measurements during the previous winter ${ }^{4}$ showed that clouding-over virtually 
TABLE IV

Radiosonde ObSERvations

Nov. 23, 26, and 28, 1939, at Blue Hill

Including Reductions to Effective Moisture Path Lengths

\begin{tabular}{|c|c|c|c|c|c|c|c|c|c|}
\hline 0 & 996.0 & $+\mathrm{I} .40$ & $3 \cdot 97$ & & 600 & 924.4 & -0.7 & 3.24 & I. 7656 \\
\hline 5 & 995.4 & +1.98 & 3.86 & 0.0153 & 700 & $9 \pm 2.7$ & - I.7 & 3.00 & 2.0024 \\
\hline IO & 994.8 & +2.29 & $3 \cdot 7^{8}$ & .0302 & 800 & 901.3 & -1.4 & 2.79 & 2.2212 \\
\hline I5 & 994.2 & +2.46 & 3.69 & .0448 & 900 & 890.2 & 0.0 & 2.95 & $2.43^{62}$ \\
\hline 20 & 993.6 & +2.50 & $3 \cdot 77$ & .0593 & 1000 & $879 \cdot 3$ & +1.2 & 3.07 & 2.6586 \\
\hline 30 & 992.3 & +2.49 & $3.9 I$ & .0892 & 1250 & 852.5 & +1.3 & 3.05 & 3.2172 \\
\hline I 25 & 980.6 & +2.37 & $4 \cdot 33$ & .3996 & 2500 & 728.2 & -5.0 & I. 73 & $5 \cdot 3212$ \\
\hline 150 & 977.6 & +2.20 & 4.28 & .4828 & 2750 & $705 \cdot 5$ & -6.6 & I. 48 & $5 \cdot 5924$ \\
\hline 175 & 974.6 & +2.02 & $4 \cdot 14$ & $.564 I$ & 3000 & 683.5 & -8.3 & I. 29 & 5.8248 \\
\hline 200 & 971.6 & +1.47 & 4.05 & .6434 & 3500 & 640.9 & - II. 5 & $0.9^{8}$ & 6.2024 \\
\hline 250 & 965.7 & tr.o & $3 \cdot 94$ & .7979 & 4000 & $599 \cdot 5$ & $-\mathrm{I}_{4} \cdot 9$ & 0.647 & 6.4725 \\
\hline 300 & 959.8 & +0.7 & 3.86 & $.948 \mathrm{I}$ & 4500 & $56 \mathrm{I} .0$ & -18.1 & 0.437 & 6.6454 \\
\hline 350 & 953.9 & +0.3 & $3 \cdot 77$ & I. 0950 & 5000 & $524 \cdot 9$ & $-2 I \cdot 5$ & 0.287 & 6.7604 \\
\hline 400 & 948.0 & to. I & 3.64 & I. 2368 & 6000 & 457.4 & -28.3 & 0.147 & $6.892 \mathrm{I}$ \\
\hline 450 & 942.0 & +o.I & $3 \cdot 59$ & 1.3751 & 7000 & 397.1 & -35.5 & 0.060 & 6.9532 \\
\hline 500 & 936.0 & to. 1 & $3 \cdot 49$ & I. $5 \mathrm{IO} 2$ & 8000 & 343.1 & $-42 \cdot 3$ & & 6.9782 \\
\hline
\end{tabular}

stopped nocturnal-radiation cooling, it seems proper to ascribe unreasonably low net readings to partial cloud interception.

The means used to correct for cloud interception was the plotting of the net radiationintensity curve for each traverse to scales so chosen that steady clear-sky radiation would plot nearly as a straight line from the minimum-moisture path (zenith sighting) well out toward extremely long paths (near-horizon sighting), at least until the change in temperature along the path becomes more important than the change in moisture content. As mentioned above, this is accomplished by plotting net radiation on semi-log scales. (See Fig. 6.)

The dependable observations for total incoming radiation for $45^{\circ}, 75^{\frac{1}{2}}$, and $84^{\frac{1}{2}}$ from the zenith respectively give $6.37,7.18$, and 7.96 calories per square-centimeter hour steradian. The net radiation found at Blue Hill between zenith angles of $70^{\circ}$ and $85^{\circ}$ appears to be slightly lower than those reported by DuBois, ${ }^{20}$ Linke, ${ }^{21}$ and Süssenberger. ${ }^{22}$ Direct comparison of results cannot be made accurately without alllowance for different aperture angles of view.

Radiosonde Observations-Nov. 23, 26, 28, 1939, at Blue Hill. Table IV gives the threenight average of observations of atmospheric pressure, temperature, and water-vapor pressure at the surface and on the tower at Blue Hill and in the free air by radiosonde. On Nov. 28, unfortunately, the radiosonde temperature device failed to start promptly. This gap has been filled in by comparison with Nov. 23 and Nov. 26 and by using maximum ground air temperature to establish the probable lapse rate below the inversion. The inversion level is indicated by the change in relative humidity, of which the record is 
complete. The only other critical assumption is of moisture on Nov. 23 between the barometric pressures of 972 and $900 \mathrm{mb}$. This is assumed to be a linear change.

The effective moisture path lengths given in Table IV are only for the zenith direction because the isotherms are not level near the hilltop. For other sighting angles special local variation is assumed, based on a dry adiabatic lapse rate extending downward from the I00-meter value 1000 meters away horizontally. This gives the basic $3 \cdot 4^{\circ} \mathrm{C}$ horizontal temperature assumed, which is $2^{\circ} \mathrm{C}$ warmer than at the hilltop. A graduated adjustment has been assumed for the intervening space, using a full streamline effect following the hill surface; then partial streamlines at higher elevations, vanishing at Ioo meters above the hilltop. ${ }^{23}$ No hilltop distortion of moisture distribution has been assumed. The result of the lowered isotherms is negligible for the $24^{\frac{1}{2}}$ and $45^{\circ}$ sighting angles as compared with secant values, but for observations near the horizon there is a small increase in emissive power.

Temperature Distribution Along Sighting Paths Through Water Vapor. To evaluate the mean temperature for each interval of moisture path length it is convenient to read the local temperature at given distances along the sighting angles on the graph of hilltop isotherms and then replot these against moisture path length. For the longer path lengths one may well reduce the total moisture path (to interval center) to the zenith equivalent, (by dividing by the secant of the angle of sight from the zenith), and read the temperature from a plot of the zenith temperature vs. moisture.

\section{REFERENCES}

I. Young, Floyd D., Senior meteorologist, U. S. Weather Bureau. Frost and the Prevention of Frost Damage. U. S. Dept. of Agriculture, Farmers' Bul. No. I 588, Superintendent of Documents, Washington D. C. (price Io cents), revised Dec. I940, $65 \mathrm{p}$.

2. Schoonover, Warren R., F. A. Brooks, and H. B. Walker. Protection of Orchards against Frost. Agr. Ext. Circular I I I, University of California, Berkeley, Calif., April 1939, $70 \mathrm{p}$.

3. Kepner, Robert A. Operation of Orchard Heaters. Agr. Exp. Sta. Bul. 643, University of California, Berkeley, Calif., Oct. I 940, 32 p.

4. Brooks, F. A., C. Lorenzen, Jr., and L. M. K. Boelter. Observations of Nocturnal Winter Atmospheric Radiation in California. Bul. Am. Met. Soc., v. 20, No. Io, Dec. I939, pp. 433-39.

5. Elsasser, W. M. An Atmospheric Radiation Chart and its Use. Quart. Jl. Roy. Met. Soc., v. 66, supplement I940, pp. 4I-56.

6. Hottel, H. C. and H. G. Mangelsdorf. Heat Transmission by Radiation from Non-luminous Gases, II, Experimental study of carbon dioxide and water vapor. Trans. Amer. Inst. Chem. Eng., v. 3 I, No. 3 .

7. Wulf, Dr. Oliver R. (U. S. Weather Bureau, Research Department, Washington D. C.), in personal discussion, Dec. 8, I939.

8. Marvin, C. F., Psychrometric Tables for Vapor Pressure, Relative Humidity, and Temperature of the Dew Point. U. S. Dept. of Agric., Weather Bureau publication No. 235 ; U. S. Government Printing Office, Washington, D. C., I937, p. 9.

9. Pexeris, C. L. Notes on Brunt's Formula for Nocturnal Radiation of the Atmosphere. Astrophys. Jour., v. 79, No. 4, May I934, pp. 44I-47. 
io. Ladenburg, R. and F. Reiche. Über selective Absorption. Annalen der Physik, vierte folge, Band 42, No. II, Aug. I9I3, p. I8I-209.

i i. Paneth, F. A. The Chemical Composition of the Atmosphere. Quart. Jl. Roy. Met. Soc., v. 63, July 1937, p. 433 .

I2. Hottel and Mangelsdorf, op. cit. Figs. 4 and il.

i3. Pettit, Edison, and Seth B. Nicholson. Lunar Radiation and Temperatures. Astrophys. Jour., v. 7I, I930, pp. 102-I35; or Contributions from Mt. Wilson Observatory, No. 392.

I4. Petrit, Edison. Lunar Radiation as Related to Phase. Astrophys. Jour., v. 81, I935, pp. 17-36; or Contributions from the Mt. Wilson Observatory, No. 504.

I 5. Pettit, Edison. Mt. Wilson Observatory, Pasadena, California; personal correspondence Aug. 20 and Oct. 8 and 28, I940. Atmospheric observations April 20, I924. Galvanometer deflections of $338,33 \mathrm{I}, 320,304$, and 275 for secant of zenith distances of I.00, I.2I, I.26, I.7I, and 2.30 respectively. Air temperature $10 \frac{1}{2}^{\circ} \mathrm{C}$, equivalent water 4 to $5 \mathrm{~mm}$. Arcturus gave $82 \mathrm{~mm}$ deflection when sec $\mathrm{Z}=\mathrm{I} .35$. Receiver $0.62 \times 0.62 \mathrm{~mm}$, effective reflector area $45890 \mathrm{~cm}^{2}$.

I6. ElsasSER, op. cit. p. 43, bottom note.

17. MüGge, R., and F. Möller. Über Abkühlungen in der freien Atmosphäre infolge der langwelligen Strahlung des Wasserdampfes. Met. Zeits., v. 49 (March 1932), Fig. I, p. 97. Also Zts f. Geophys., v. 8 (1932), p. 53; Beitr. Phys. d. freien Atm., v. 20 (I932), p. 220.

18. Ashburn, Edward V. The Vertical Transfer of Radiation Through Atmospheric Temperature Inversions. Master's Thesis, Dept. of Aeronautical Engineering, Massachusetts Institute of Technology, I940.

19. Rietz, H. L., Editor in Chief. Handbook of Mathematical Statistics. Houghton Mifflin Co., I924, p. 77 (ratio of $0.8454 / 0.6745$ ).

20. DuBois, P. Nächtliche effektive Ausstrahlung. Gerl. Beitr. z. Geophys., v. 22, I929, p. $4 \mathrm{I}$.

2I. Linke, F. Die Nächtliche effektive Ausstrahlung unter verschiedenen Zenitdistanzen. Met. Zeits., v. 48, No. I, Jan. I93I, pp. 25-3I.

22. Süssenberger, Erich. Die Nächtliche effektive Ausstrahlung unter verschiedenen Zenitdistanzen. Met. Zeits., v. 52, No. 4, April 1935, pp. I 29-32.

23. Clayton, H. Helm. The Diurnal and Annual Periods of Temperature ... in Free Air at Blue Hill. Annals of the Astronomical Observatory of Harvard College, v. 58, part I, Cambrige, I904.

24. Strong, John. Study of Atmospheric Absorption and Emission in the Infrared Spectrum. Jour. Franklin Inst., v. 232, No. I, July I94I, p. 2. 
